\title{
A Percepção da Utilização do Marketing Digital no Comércio Varejista da Cidade de Caririaçu - CE
}

\author{
Jose Italo Roseno Vilarl; Herminig Everson Matos Queiroz ${ }^{2}$; \\ Dávila Maria Feitosa Dantas ${ }^{3}$ Josefa Zilda Roseno Silva ${ }^{4}$
}

\begin{abstract}
Resumo: $\mathrm{O}$ estudo tem como finalidade apresentar os benefícios advindos da utilização da ferramenta Marketing Digital dentro do comércio varejista juntamente com as novas mídias sociais. Para tanto, em uma primeira etapa, foi executada uma pesquisa bibliográfica com a finalidade de definir marketing digital, avaliando o seu desenvolvimento no comércio do município, entendendo a sua importância e os benefícios oriundos do mesmo. Em uma segunda etapa, foi realizado um levantamento de dados através de questionários praticada com habitantes do centro comercial da cidade de Caririaçu - CE. A partir do estudo realizado, buscou-se analisar se o marketing digital das empresas está chegando até os seus clientes de forma eficaz e explorar a utilização do marketing juntos as novas mídias sociais, visando também o aumento e consolidação de uma melhor comunicação entre a organização e o público.
\end{abstract}

Palavras-Chave: Marketing Digital. Canais de Comunicação. Mídias Sociais. Comércio Varejista.

\section{Perception of the Use of Digital Marketing in Retail Sale Market of Caririaçu, State of Ceará}

\begin{abstract}
The study aims to present the benefits of using the Digital Marketing tool within the scope of the editorial project. To do so, in the first stage, a bibliographic research was put in order to define digital marketing, to evaluate its own research, to include its importance and the benefits of it. In a second stage, a data survey was carried out through questionnaires carried out with the population of the commercial center of the city of CaririacuCE. From the study conducted, we sought to analyze the digital marketing of companies that are reaching out to their customers effectively and exploit a marketing use like new and the public.
\end{abstract}

Keywords: Digital marketing. Communication channels. Social media. Retail business.

\section{Introdução}

É importante destacar o atual cenário de competitividade no setor de comércio, onde os consumidores estão mais exigentes e buscam empresas que possam atender as suas

\footnotetext{
${ }^{1}$ Graduando do Curso de Administração do Centro Universitário Doutor Leão Sampaio/UNILEÃO, Juazeiro do Norte, Brasil. - e-mail: ítalo.roseno@hotmail.com

${ }^{2}$ Mestrado Profissional em Computação pela Universidade Federal de Pernambuco, Brasil. Professor Orientador do Centro Universitário Doutor Leão Sampaio/UNILEÃO - e-mail: everson@ leaosampaio.edu.br

${ }^{3}$ Centro Universitário Doutor Leão Sampaio/UNILEÃO: davilamariafeitosa@gmail.com

${ }^{4}$ Centro Universitário Doutor Leão Sampaio/UNILEÃO: selmaroseno@ hotmail.com 
necessidades, levando em consideração a qualidade dos produtos, além dos serviços e os preços mais acessíveis no mercado.

Com a atual situação de competição em que se encontra o comércio, as organizações, desde grandes empresas até pequenos negócios autônomos, desenvolvem a necessidade de se adaptarem as novas exigências dos consumidores para assim atenderem os desejos do seu público-alvo. Com isso, surge o dever de elaborar estratégias que sejam capazes de alavancar o nome da empresa tornando-a competitiva.

A atividade do Marketing Digital no Brasil teve origem no ano de 1950, quando uma grande massa de consumidores e comerciantes sentiram a necessidade de criar um modelo inovador que facilitasse as relações comerciais diante da nova dinâmica de mercado resultante da nova reestruturação produtiva da economia urbana que surgia no país. Outro grande fator que causou a ascensão do marketing digital no Brasil foi a chegada de empresas de capital internacional norte-americana de produtos de limpeza e produtos alimentícios, que enxergaram oportunidades e começaram a investir no mercado brasileiro, que se mostrava um bom lugar para implementar esses tipos de produtos. (GRACIOSO, 2013).

A pesquisa ora apresentada tem como objetivo analisar a influência do marketing digital para os clientes do segmento varejista da cidade de Caririaçu - CE em função das novas mídias de comunicação, e tem como objetivo específico conceituar a importância da ferramenta marketing digital, identificar vantagens que essa ferramenta possa levar aos comerciantes e empreendedores e verificar se o marketing digital influencia no processo de compra dos consumidores.

Para alcançar tal objetivo, é essencial a compreensão da concepção de marketing e suas ferramentas, assim, buscando desenvolver uma relação comunicativa mais eficaz entre a empresa e seus consumidores e reafirmando seu espaço no mercado, a partir de estratégias que venham fortalecer tais relações com base no marketing, levando um diferencial para empresa e contribuindo para torna-la estável no mercado local. Uma de suas ferramentas que tem chamado atenção é o Marketing Digital, pois ele tem ampliado o campo de visão para as empresas do setor de comércio e demais serviços, dando-lhes mais visibilidade atraindo o mercado consumidor e estimulando a forma de pensar entre os profissionais que trabalham com do Marketing, possibilitando aos mesmos métodos mais diretos de levar produtos ou serviços aos consumidores, em tempo hábil, e de uma maneira em que os mesmos possam se sentir satisfeitos. Kotler (2000) diz que o marketing tem como missão criar, promover e fornecer bens 
e serviços a clientes. O profissional do marketing apresenta métodos para estimular a demanda de clientes pelos produtos de uma empresa.

O presente trabalho trata-se de uma pesquisa de gênero exploratório e tem uma abordagem quantitativa. Desse modo, o mesmo divide-se em três etapas, visto que a primeira apresenta um levantamento bibliográfico onde foram utilizadas diversas fontes de pesquisa, tais como, livros, artigos científicos, jornais, periódicos, sites de internet e entre outros. A segunda etapa aborda uma pesquisa de campo através de questionários estruturados aplicados aos moradores da cidade de Caririaçu - CE, onde os mesmos foram escolhidos por meio de amostragem aleatória simples. No terceiro momento foi realizada a sistematização das informações coletados na pesquisa e a análise dos dados com auxílio de algumas ferramentas, especificamente, Google Forms e o Microsoft Excel 2013.

\section{Referencial Teórico}

\section{Marketing}

Marketing não apenas é a ação de vender ou propagar algo, estas são somente atividades realizadas pelo marketing. Julga-se que é necessário compreender os desejos dos clientes para melhor atendê-los e consequentemente satisfazê-los. O objetivo é atender tão bem o consumidor que o produto ou serviço o atraia e venda-se sozinho, e o cliente faça uma auto avaliação e considere-se pronto para comprar. (DRUCKER, 1973)

Com o grande uso da internet, mídias e redes sociais e várias outras ferramentas de comunicação, criou-se um grande desafio para as organizações. Os novos cenários estão cada vez mais exigentes onde os modelos monótonos de gestão não encontram mais espaço. Com isso, se as organizações não buscarem maneiras de se atualizarem para adaptar-se aos modelos atuais em que o mercado se encontra, as mesmas perderão seu espaço e dificilmente conseguirão sobreviver. (PEREIRA, 2014)

De acordo com Kotler (2000), marketing aplica-se em organizações, informações, produtos, serviços, ideias, lugares, pessoas, eventos e experiências. Profissionais da área do marketing apontam determinados grupos de consumidores, identificam suas carências e necessidades, e logo após, elaboram produtos direcionados para um determinado segmento. $\mathrm{O}$ marketing busca analisar os conceitos e atender um público-alvo. 
Ainda segundo Kotler (2005), "Desejos tornam-se demandas quando apoiados por poder de compra. O marketing cria necessidades e induz pessoas a comprarem coisas que não desejam."

\section{Marketing Digital}

Solomon (2011) afirma que o marketing digital dispõe de uma maior eficiência de segmentação, facilidade e uma comunicação personalizada, e comparada aos métodos de comunicações convencionais, acaba se tornando muito mais acessível. É de grande importância entender que o marketing digital se distingue do marketing convencional, pois seu maior foco de interação se dá ao uso da internet para alcançar um melhor relacionamento com o seu público-alvo, de maneira segmentada, onde todos os tipos de necessidades sejam alcançadas.

De acordo com Chleba (2000) a maior força do marketing na internet, encontra-se na grande interação em toda a rede, pois, se alguma empresa ou profissional pretende mostrar-se vivos no mercado é indispensável considerar que a internet é um de seus principais recursos. O marketing digital conceitua-se como a utilização das ferramentas de marketing no ambiente digital, especialmente na internet, que por sua vez, é atualmente a maior rede de comunicação existente.

A partir da comunicação entre internet e marketing, pode-se implantar no ambiente digital uma marca resistente no mercado online. Loubete, Alves, Galvão (2009) relatam várias ferramentas capazes de serem aplicadas no marketing digital, como, e-mail marketing, blogs e videologs, anúncios, fóruns, otimização para sites de busca, websites promocionais, entre outros.

O marketing digital torna-se de fundamental importância para a compreensão dos processos de tomadas de decisões do consumidor, pois é desta ferramenta que é gerada todas sensações e desejos sobre o produto ou serviço, e até impulsionar o indivíduo a realizar ou não a compra. Outro ponto de extrema importância é o pós-compra, pois é nesta etapa onde o cliente poderá tornar-se um consumidor fiel a marca. (CARO, 2010)

Com tudo, o marketing digital impulsionou um complexo de oportunidades que juntas formaram um mecanismo de sucesso nos resultados das organizações, atingindo seus meios de comunicação, fornecedores, suas estratégias e ainda tornando-se um meio de captação e 
fidelização de novos clientes, garantindo assim a satisfação do seu consumidor final. (VAZ, 2010)

\section{Canais de Comunicação}

Lewandowisk (1982) diz que a comunicação é definida como o "entendimento interpessoal, participação intencional ou socialização de informações com ajuda de sinais, sistemas de signos, sobretudo, através da linguagem”. Já Ferreira (1986) afirma que comunicação é a ação de lançar, conduzir e adquirir informações por meio de técnicas ou processos capazes de debater e trocar ideias capazes de levar o bom entendimento entre pessoas.

Mangols e Faulds (2009) afirmam que a comunicação de marketing é a orientação principal que as empresas devem seguir para manter uma boa comunicação com o seu mercadoalvo, tendo um maior controle do mix promocional, publicidade, relações públicas, venda pessoal, promoções de venda e marketing direto, e assim, alcançar os objetivos traçados pela organização. Lovelock e Wirtz (2006) dizia que com uma comunicação eficaz, os consumidores podem ter um maior conhecimento de como encontrar a organização, e de como adquirir os seus produtos ou serviços.

Como diz Amaral (2008), as metas fundamentais da comunicação de marketing são dar uma maior visibilidade a uma empresa e seus serviços e fidelizar clientes, deixando-os sempre bem informados sobre a atual situação da empresa. Grönroos (2004) afirma que as comunicações de marketing como websites, relações públicas e vendas e publicidade, destacam e podem até formar imagem.

Com a globalização e a evolução das exigências do mercado, as organizações viram-se obrigadas a transformar sua maneira de gerenciar todos os seus processos. De acordo com Marchesi (2005), as empresas, para obter uma melhor comunicação, deve rever seus conceitos e se manterem atualizadas com as novas exigências propostas pelos consumidores, para com isso buscarem uma forma de satisfazê-los atendendo toda a demanda.

\section{Importância das Mídias Sociais}

Nascimento (2016) discorre que as redes sociais são de total importância para implantação de estratégias capazes de tornar uma empresa competitiva, e consequentemente, 
levar as organizações aos resultados esperados. As informações apuradas nas redes sociais são opiniões voluntariamente concedidas pelos usuários das redes, proporcionando assim, oportunidades para as empresas conhecerem melhor seus consumidores e suas necessidades, e assim, definir seu mercado-alvo.

Com isso, constituiu-se um novo conceito de marketing, o marketing individualizado, que por sua vez, mostra-se ser mais versátil que o marketing direto de Rogers e Pappers (1994), onde o consumidor tem um tratamento particularmente interativo e um melhor relacionamento entre cliente e empresa. Portanto, o comprador estabelece de uma forma mais direta os seus desejos de produto ou serviço que mais lhe satisfaz. A cada dia, os consumidores tornam-se cada vez mais exigentes, buscando sempre os melhores preços, boa qualidade, maior velocidade nos serviços ou entregas de produtos, e que as empresas estejam sempre lhes surpreendendo com inovações. Logo, os profissionais do marketing buscam atender as necessidades de maneira rápida e eficiente.

Com a evolução da tecnologia, o mercado vem crescendo e se adaptando as inovações. Algumas potências sociais de grande importância como a concorrência ampliada, a globalização, onde cada vez mais as pessoas estão se comunicando com mensagens instantâneas ao redor do mundo, o aumento do poder do cliente, etc., interligadas, já criaram e continuam criando novos conceitos, novas estratégias e novas oportunidades. Mas, como qualquer novidade no mercado, também acarretam novos desafios. (KOTLER, 2006)

Hoje, o estudo do comportamento do cliente é tão importante, que uma simples postagem em uma rede social, website, blog, entre outros, pode elevar ou destruir a imagem de uma marca ou produto. Isso se dá, devido à grande comunicação de usuários da rede em todo o mundo. Para o marketing digital, o planejamento e criação de estratégias das organizações, as mídias sociais e o conhecimento mais aprofundado das empresas com seus clientes, é tão importante que não seria exagero afirmar que as empresas que deixarem de lado essas ferramentas, tendem a perder espaço no mercado. (KOTLER, 2006)

\section{Comércio Varejista da Cidade de Caririaçu - CE}

O Instituto de Pesquisa e Estratégia Econômica do Ceará (IPECE, 2013), é um órgão do governo que tem como responsabilidade a criação de estudos, pesquisas e informações 
socioeconômicas que permitem a análise e avaliação de programas e estratégias voltadas para o desenvolvimento do estado do Ceará.

De acordo com pesquisas realizadas na última década pelo IPECE (2013) na cidade de Caririaçu - CE, 287 estabelecimentos comercias estão devidamente registrados nos órgãos responsáveis do município, sendo 285 voltados ao varejo e apenas 2 ao atacado. Ou seja, uma maioria absoluta do comércio do varejo.

Segundo o IPECE (2013), o PIB a preço de mercado encontra-se em $\mathrm{R} \$ 130.875,00$, enquanto o PIB per capta encontra-se em $\mathrm{R} \$ 4.880,00$. Dividindo esses dados em setores do comércio da cidade de Caririaçu - CE, a agropecuária concentra apenas 9,74\% e a indústria $5,78 \%$, enquanto o setor de serviços concentra sozinho $84,49 \%$ de todo o PIB da cidade.

Com esse constante crescimento no mercado é importante que os empresários trabalhem com o marketing digital para alavancar suas vendas e fidelizar seus clientes, e com um bom planeamento esta ferramenta poderá auxiliar de forma significativa os gestores e proprietários das organizações, tornando-os mais competitivos no mercado, melhorando seus resultados e por fim, alcançando seus objetivos.

\section{Metodologia}

Esta pesquisa caracterizou-se por um estudo de gênero exploratório, que segundo Gil (2007), tem como objetivo construir hipóteses e levar uma maior familiaridade com o problema. Quanto a sua abordagem, o trabalho tem um caráter quantitativo, onde os resultados da pesquisa podem ser quantificados em informações numéricas, buscando sempre a objetividade dos mesmos. (FRANKENTHAL, 2016)

Deste modo, destaca-se que a pesquisa está dividida em três etapas, visto que a primeira trata-se de um levantamento bibliográfico em diversos meios de informações, tais como, livros, periódicos, artigos científicos, jornais, documentos oficiais, sites de internet e entre outros que abordam a discussão proposta no tema. (GIL, 2007)

No segundo momento foi realizado uma pesquisa de campo na qual para Fonseca (2002), qualifica-se como um estudo em que é feita uma coleta de informações junto a pessoas, em que pode-se utilizar diversos tipos de recursos para a realização da mesma. O método adotado para coleta de dados foi a aplicação de questionários estruturados, no qual segue-se um série ordenada de perguntas previamente determinadas, com a finalidade de receber diversas 
respostas para a mesma questão, o que leva a possibilidade de uma comparação entre as mesmas. (MARCONI \& LAKATOS,2001). Optou-se por um estudo de opinião por se tratar em buscar conhecer atitudes, pontos de vista e preferências que as pessoas têm sobre algum assunto, como também conhecer interesses, comportamentos, falhas entre outros (ALMEIDA, 1996).

A pesquisa foi executada no centro comercial do município de Caririaçu - CE, onde foram aplicados 245 questionários aos moradores e consumidores da localidade. A escolha dos entrevistados foi realizada por meio de amostragem aleatória simples, e a aplicação fez-se no bairro de maior número de comércios do segmento varejista, no qual possui diariamente um fluxo expressivo de cliente que residem em todo o território municipal, sendo eles habitantes da zona rural ou sede da cidade, mas que se deslocam frequentemente até o centro comercial para realizar suas compras. A amostragem aleatória simples pode ser definida como a escolha dos elementos que participarão da pesquisa de uma forma aleatória, mas que por sua vez, exista uma igual probabilidade no momento da escolha dos mesmos. (MALHOTRA, 2001)

Por último, foi realizado a sistematização das informações e dados coletados que serviram de base para produção do Trabalho de Conclusão de Curso (TCC). Com o auxílio de algumas ferramentas foi possível analisar e tabular todos os dados coletados. As ferramentas utilizadas para a realização deste trabalho foi o Google Forms, onde foram respondidos alguns questionário, e o Microsoft Excel 2013, que serviu para tabular e processar todos os dados coletados durante a pesquisa. Para a escolha da população ideal foi utilizado uma calculadora online de cálculo amostral, onde foi escolhida a amostra ideal para a aplicação dos questionários.

\section{Análise e Discussão dos Resultados}

A pesquisa foi realizada através de uma série de questionários com perguntas estruturadas, atendendo aos critérios existentes nos objetivos do trabalho. Com o intuito de identificar se o marketing digital das empresas do municio de Caririaçu - CE estão ou não chegando aos consumidores, as perguntas utilizadas exploraram desde o gênero e a faixa etária do entrevistado, até aspectos mais específicos como conhecimento acerca do marketing digital, acesso as mídias sócias e a importância dada a respectivos anúncios contidos nas mesmas, influência da internet no processo de decisão de compra do consumidor, divulgação do mercado local e importância da comunicação entre cliente e empresa. 
O estudo de campo utilizou-se de questionários aplicados de maneira aleatória com a população do centro da cidade de Caririaçu - CE, no período de 23/10/2018 a 26/10/2018. A amostra da pesquisa foi calculada através de um cálculo amostral onde foi utilizado uma população de 30.000 pessoas, que correspondem aproximadamente a população total do município, considerando um nível de confiança de $95 \%$ e uma margem de erro de $5 \%$. Como resultado do cálculo, encontrou-se uma amostra ideal de 380 entrevistados, porém só foi possível aplicar 245 questionários por ocasião de limitações da pesquisa, pois muitas pessoas não tinham disponibilidade para participar do estudo, e por isso não alcançou-se um quantitativo maior.

Calculo utilizado:

$$
n=\frac{N \cdot Z^{2} \cdot p \cdot(1-p)}{Z^{2} \cdot p \cdot(1-p)+e^{2} \cdot(N-1)}
$$

Onde:

n - amostra calculada

$\mathrm{N}$ - população

Z - variável normal padronizada associada ao nível de confiança

$\mathrm{p}$ - verdadeira probabilidade do evento

e - erro amostral

O primeiro gráfico traz uma representação do gênero dos entrevistados, masculino e feminino, levando em consideração que os mesmo foram escolhidos de forma aleatória, com a mesma quantidade de pessoas abordadas entre um gênero e outro, e com isso, buscou-se obter uma maior precisão nas informações cedidas pelos mesmos.

Gráfico 1: Gênero dos entrevistados

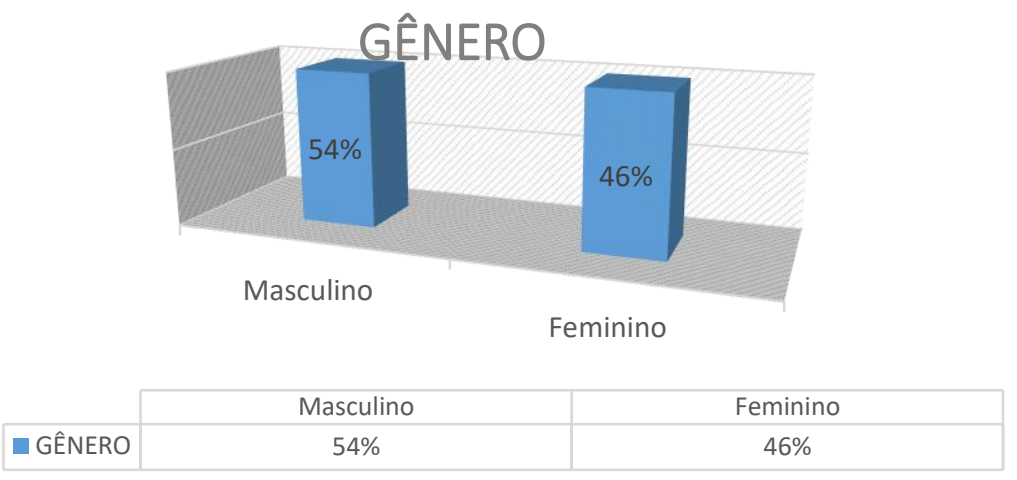

Fonte: Dados da pesquisa 2018

O esboço acima mostra que o público masculino correspondeu a $54 \%$ das pessoas que se dispuseram a responder o questionário, enquanto o público feminino ficou um pouco atrás com $46 \%$. Durante a pesquisa foi possível notar uma maior indisponibilidade do público 
feminino ao serem abordadas para a realização dos questionários, as mesmas afirmaram não ter tempo, ou não gostar de participar de pesquisas.

O gráfico 2 representa a faixa etária da população da pesquisa, onde as pessoas a serem entrevistadas deveriam possuir uma idade acima de 16 anos. A idade mínima considerada foi escolhida a partir de uma estimativa em que os mesmos possam ter um maior entendimento acerca dos conteúdos contidos nos questionários a serem respondidos.

Gráfico 02: Faixa etária dos entrevistados

FAIXA ETÁRIA

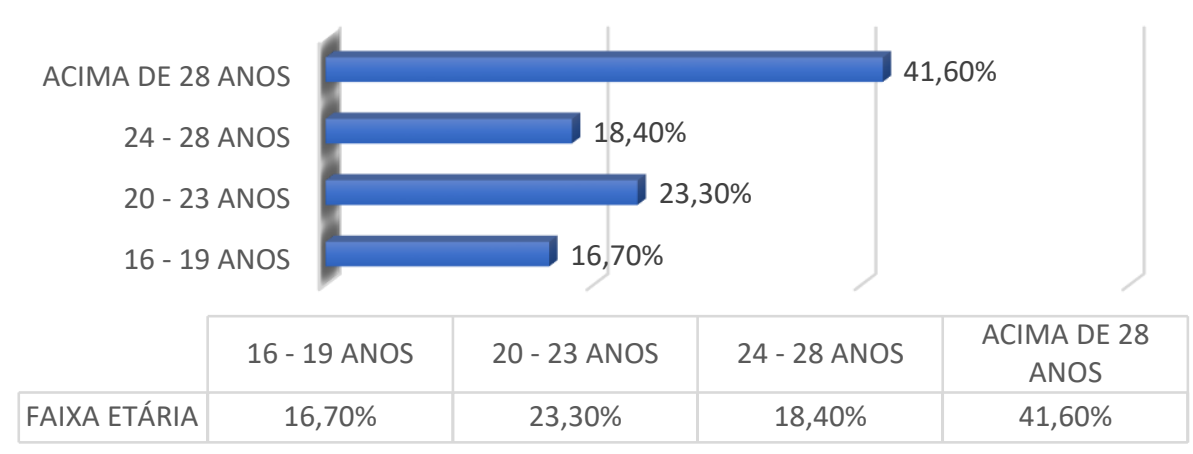

Fonte: Dados da pesquisa 2018

Foi possível analisar que o maior índice foi registrado no público acima de 28 anos, que correspondeu a 41,6\% dos entrevistados. Em contra partida com menor quantidade ficou o público entre 16 e 19 anos, com apenas $16,7 \%$ das amostras.

Acredita-se que pela pesquisa ter sido realizada no centro comercial, onde além de comércios de variados segmentos, está presente também uma grande feira de frutas e verduras, a população composta ali pertence a um público com uma idade mais elevada, por ser um lugar de compras rápidas e funcionar principalmente no período da manhã, onde o público mais jovem está na escola e as pessoas fazem as compras para o almoço.

No que diz respeito ao nível de conhecimento dos entrevistados em relação aos seus entendimentos acerca do marketing digital, o gráfico 3 traz uma análise do número de pessoas que admitem conhecer esta ferramenta.

Gráfico 3: Conhecimento acerca da ferramenta Marketing Digital 


\section{CONHECIMENTO SOBRE O MARKETING}

DIGITAL

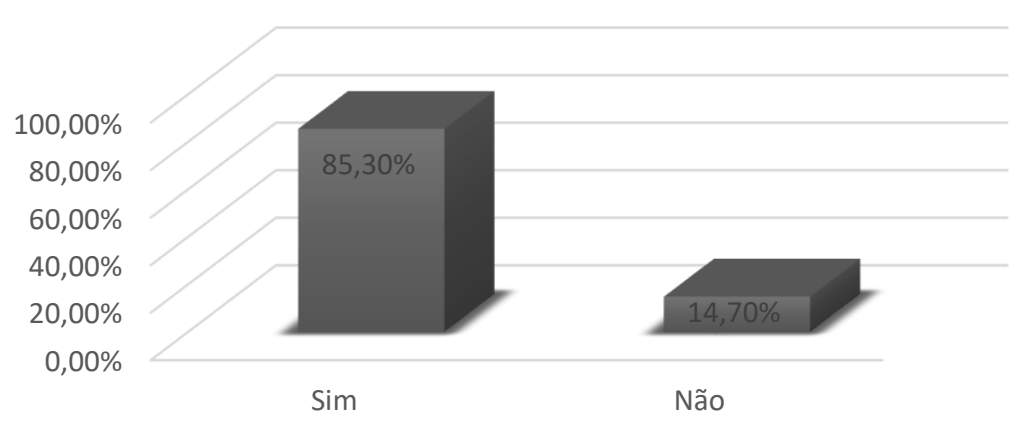

Fonte: Dados da pesquisa 2018

Com os dados coletados, obteve-se um número significativo da população onde $85,3 \%$ já tinham ouvido falar desta ferramenta, e 14,6\% relataram ainda não ter algum conhecimento a respeito do assunto abordado.

Diante desses números percebe-se a importância das pessoas já terem um conhecimento e utilizarem, direta ou indiretamente, do marketing digital, no qual pode-se dizer um contexto bem abrangente, que busca de uma forma geral levar produtos e serviços aos consumidores a partir do mundo digital, como afirma Chleba (2000), e que por sua vez, o marketing digital já encontra-se consolidado no mercado como uma ferramenta para expandir o negócio e adquirir novos clientes.

Outro aspecto questionado aos participantes da pesquisa foi em relação a frequência em que acessam as mídias sociais, que atualmente está cada vez mais presente na rotina das pessoas, seja para uso próprio ou para exercer atividades de comercialização. Nascimento (2016) dizia que as mídias sociais são de fundamental importância para a utilização de estratégias que possam tornar uma organização competitiva no mercado, pois as informações oferecidas voluntariamente pelas pessoas na internet proporcionam oportunidades para as empresas conhecerem melhor o perfil dos seus clientes, mapeando o seu perfil, entendendo as suas necessidades e assim, direcionando-os produtos que irão atender com mais facilidade os seus desejos.

Gráfico 4: Frequência de acesso em mídias sociais 


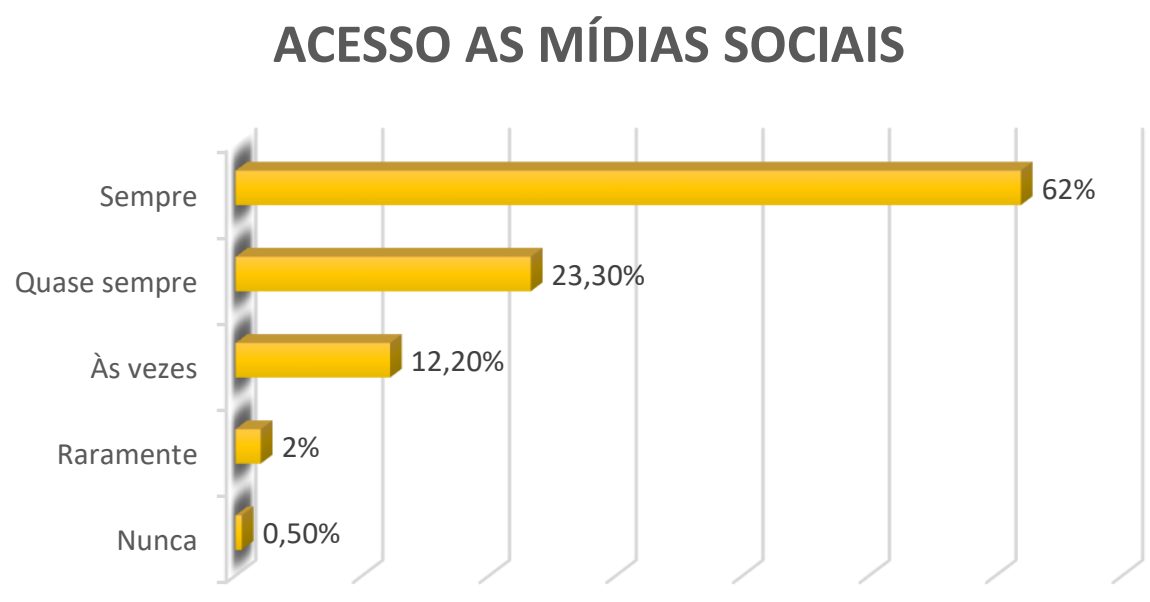

Fonte: Dados da pesquisa 2018

Comprovando essa afirmação, observa-se no gráfico 4 que diante das respostas coletadas que apenas $0,5 \%$ de toda a população abordada nunca utiliza ou utilizou das mídias sociais. Por outro lado, $62 \%$ relataram que sempre as utilizam, seja para trabalho, compras, entretenimento, noticiários ou por qualquer outro motivo. De acordo com dados coletados diretamente na secretaria de Administração da cidade de Caririaçu - CE, esse crescente número de usuários é ocasionado pela recente chegada da internet em alguns sítios da zona rural do município, localizados a quase $20 \mathrm{~km}$ de sua sede.

A partir das respostas cedidas pelos entrevistados a respeito da frequência com que os mesmos utilizam a internet, foi lançada em seguida uma pergunta que abordava qual mídia social eles mais utilizam.

Gráfico 5: Mídias sociais mais utilizadas

\section{MÍDIAS SOCIAIS}

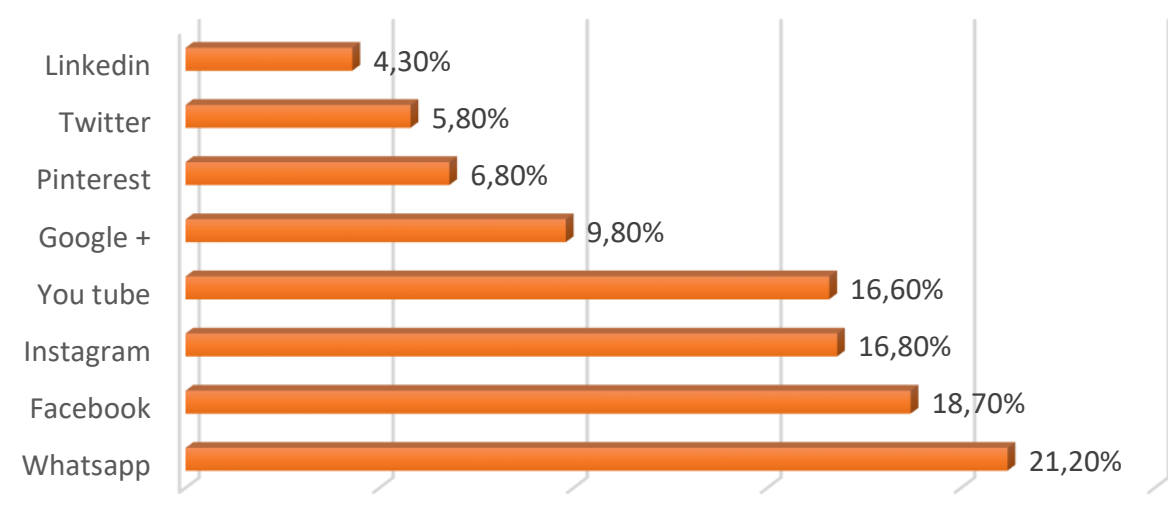

Fonte: Dados da pesquisa 2018 
Como mostra o gráfico 5 foi possível perceber que o whatsapp mostrou-se em destaque com 21,2\% dos usuários, seguindo do Facebook, Instagram, e You tube, com 18,7\%, 16,8\% e $16,6 \%$ respectivamente.

Os resultados obtidos da pesquisa possibilitam a percepção dos gestores do comércio varejista da cidade a entenderem em quais mídias devem investir em anúncios para divulgar os seus produtos e atingir um maior número de clientes, já que para Kotler (2006), uma organização com um bom planejamento de estratégias para as mídias sociais é essencial, e que organizações que não investirem nessa ferramenta tendem a perder espaço no mercado.

Com o crescente aumento de usuários na internet, o uso de estratégias de atendimento ao cliente se veem mais comum quando os caminho são as mídias sociais. Esse expressivo meio de comunicação tem oferecido as empresas novas oportunidades de conhecer melhor o seu público-alvo, mapear os seus interesses e necessidades e entender os seus desejos de acordo com as postagens publicadas pelos usuários na rede.

A partir dessas informações cedidas pelas pessoas de maneira não proposital, os comerciantes podem criar anúncios personalizados que irão chamar a atenção dos seus consumidores, fato este destacado por Solomon (2011).

Gráfico 6: Importância dada pelos usuários aos anúncios da internet

\section{IMPORTÂNCIA AOS ANÚNCIOS}

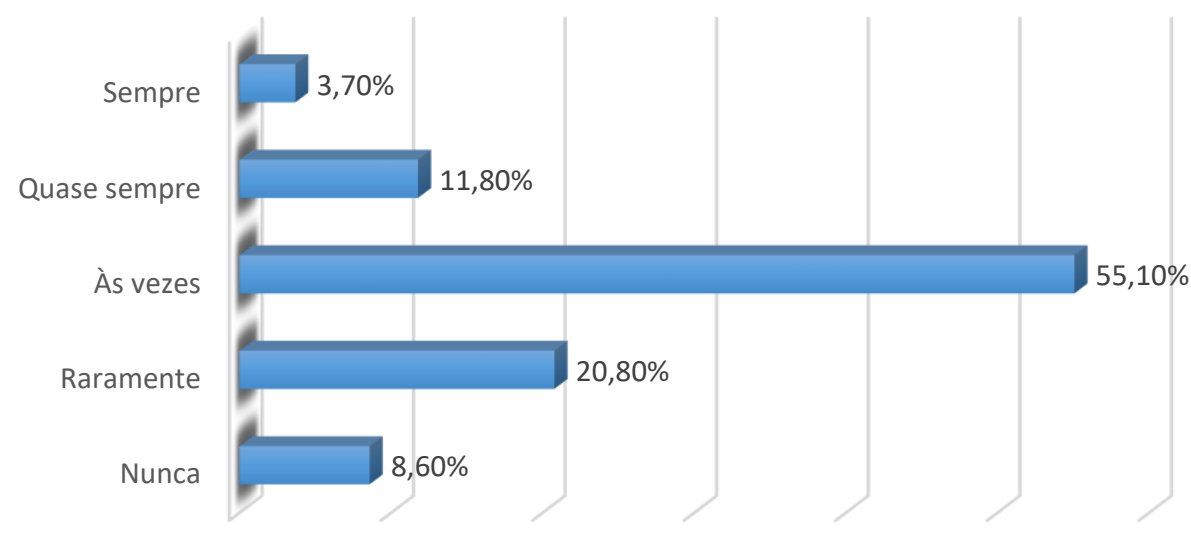

Fonte: Dados da pesquisa 2018

Mesmo com todo esse acervo de informações ofertadas pelo mundo da comunicação virtual, ao serem questionados sobre com qual frequência os entrevistados davam importância aos anúncios exibidos nas mídias sociais, apenas 3,7\% afirmaram dar importância e abrir os 
anúncios, enquanto 55,1\% declararam que nunca dão qualquer relevância a anúncios nas mídias sociais.

Diante disso é possível perceber que os anúncios e divulgações publicadas nas redes devem buscar um diferencial, sair da mesmice, e buscar métodos de chamar a atenção de quem esteja recebendo-os, caso contrário, as pessoas que receberem esses anúncios não irão se sentir instigadas a abrirem para saber mais sobre os mesmos.

O gráfico 7 aborda a influência que a internet possui na tomada de decisão do consumidor no momento da compra, levando em consideração as informações de todos os produtos que as mídias sociais e a internet levam até os clientes, buscando assim criar um desejo de obter um determinado produto, mesmo que a pessoa não possua uma necessidade de comprar aquilo.

Gráfico 7: Influência da internet na decisão de compra

\section{INFLUÊNCIA DA INTERNET}

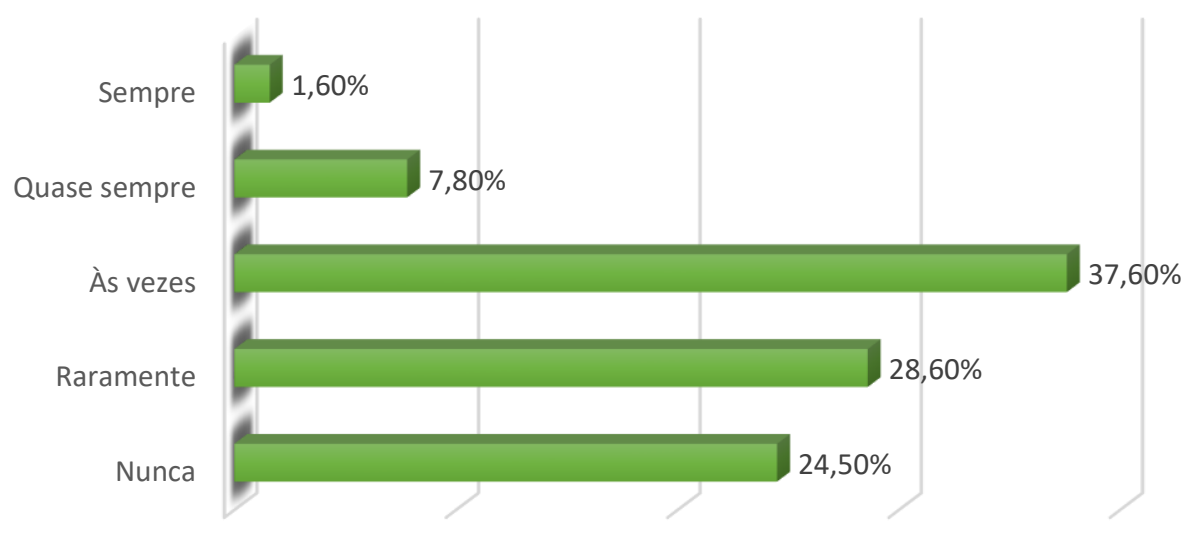

Fonte: Dados da pesquisa 2018

Ao serem perguntados com que frequência as pessoas são influenciadas pela internet a comprarem coisas, apenas 1,6\% admitiram sempre serem influenciado. Por outro lado, 24,5\% afirmaram nunca serem influenciados pela internet para realizar suas compras.

Desse modo, a internet ligada com o a ferramenta marketing digital se tornou de suma importância para o sucesso das organizações. Para Kotler (2005), o marketing cria desejos e induz as pessoas a comprarem coisas que elas não necessitam. A criação desse desejo é um dos objetivos do marketing digital, que busca levar produtos e serviços aos consumidores e, com isso, eles efetuem a compra. 
Em antemão, o gráfico 8 apresenta a frequência com que os entrevistados afirmam encontrar anúncios ou algum outro tipo de divulgação das empresas da cidade nas mídias sociais em que utilizam.

Gráfico 8: Divulgação do mercado local nas mídias sociais

\section{MERCADO LOCAL}

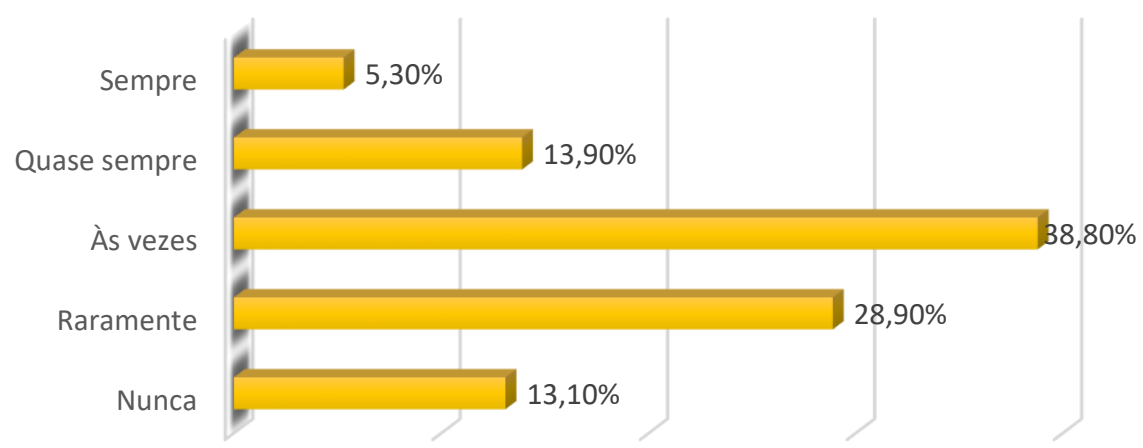

Fonte: Dados da pesquisa 2018

A partir da pesquisa realizada foi possível perceber que 38,8\% dos usuários as vezes encontram divulgações do comércio local, e que apenas 5,3\% alegam sempre ver anúncios em suas redes.

O que chamou mais atenção nesse questionamento foi que, levando em consideração os $62 \%$ dos entrevistados no qual relataram que sempre acessam as mídias sociais, como mostra o gráfico 4 , apenas $28,9 \%$ das pessoas afirmaram raramente se depararem com anúncios do comércio da cidade, e que $13,1 \%$ relatam nunca terem visto.

Tendo em vista que a internet utilizada como meio de divulgação é de essencial importância, os dados mostram que uma boa parte das empresas locais ainda não se utilizam das grandes oportunidades de crescimento e propagação oferecidas pelas mídias sociais, onde as empresas possuem chances de se divulgarem e se firmarem no mercado, atraindo e fidelizando mais clientes, buscando assim a satisfação em um todo para a organização e o consumidor.

Em uma outra questão, os entrevistados foram perguntados a frequência com que os mesmo em algum momento foram ou ainda são influenciados a partir do marketing digital a efetuarem compras no comércio da cidade. 
Gráfico 9: Influência do Marketing Digital nas compras do mercado local

\section{INFLUÊNCIA DO MARKETING DIGITAL}

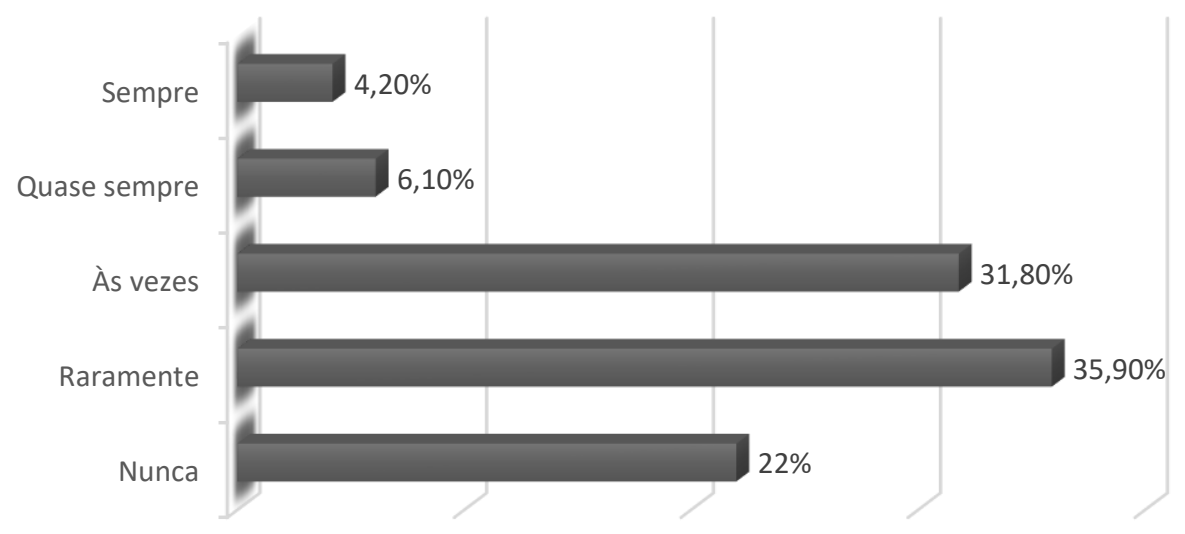

Fonte: Dados da pesquisa 2018

Analisando o gráfico 9 percebe-se que a influência do marketing digital nas compras das pessoas no mercado local ainda é muito limitado, ao serem perguntados sobre a frequência em que são influenciado, apenas 4,2\% falaram que sempre são motivados pelos anúncios encontrados nas internet, enquanto $35,9 \% \%$ relataram que raramente são influenciados a comprar e $22 \%$ que nunca foram.

Considerando os dados apresentados é possível notar que o comércio da cidade ainda não utiliza de maneira eficaz a ferramenta marketing digital, pois os clientes da localidade afirmam não se depararem com propagandas do comércio local. Com isso, os administradores e proprietários destes estabelecimentos devem planejar novas estratégias para divulgar melhor os seus produtos na internet.

O gráfico 10 apresenta qual a importância de uma boa comunicação entre a empresa e o consumidor, visto que, com essa comunicação, ambas as partes são beneficiadas, pois os clientes podem possuir um maior conhecimento sobre os produtos e serviços oferecido, e as organizações podem entender melhor o perfil dos clientes e assim estabelecer melhor quais produtos devem ser direcionados a eles com um maior grau de assertividade. 
Gráfico 10: Importância da comunicação entre empresa e cliente

\section{COMUNICAÇÃO CLIENTE/EMPRESA}

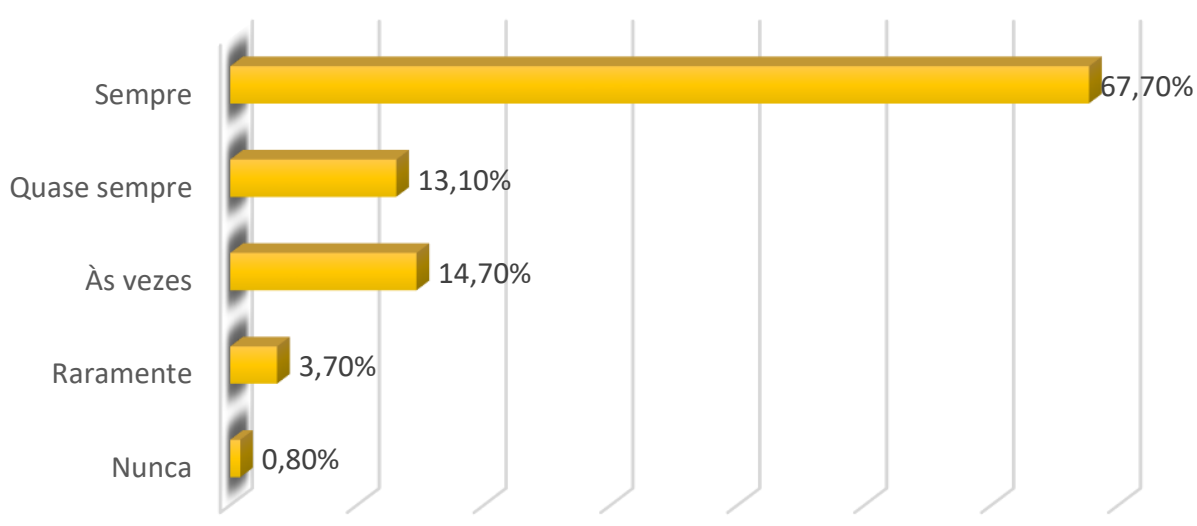

Fonte: Dados da pesquisa 2018

Após a análise foi possível perceber que apenas $0,8 \%$ dos entrevistados disseram que não consideram importante um a boa relação entre empresa e cliente. No entanto, $67,7 \%$ das pessoas afirmaram que sempre acham de grande relevância as organizações manterem uma boa comunicação, com transparência, com seus clientes.

Diante disso, pode-se perceber que os clientes estão cada vez mais em busca de manterem uma relação mais clara entre cliente/empresa, e com isso, terão um maior conhecimento de como encontrar as mesmas e como adquirir os seus produtos, o que beneficia as organizações. É a partir dessa comunicação que as empresas podem traçar estratégias para atrair os consumidores e fidelizar clientes.

\section{Considerações Finais}

O Marketing Digital não pode ser definido apenas como a prática de vender ou propagar algo na internet, pois esta são apenas algumas atividades do marketing. Inúmeras empresas prendem-se na mesmice de acreditar que a divulgação não passa de promoções de venda, banners, mala direta e entre outros métodos, mas se enganam por não saberem o quanto podem absorver dos benefícios oferecidas pelo marketing digital. $\mathrm{O}$ alto poder de segmentação de mercado proporcionado pela internet oferece que as empresas possam escolher a quem direcionar seus anúncios na internet, baseando-se no comportamento do consumidor. 
A utilização da ferramenta marketing digital proporciona as empresas diversas técnicas para conquistar e fidelizar clientes e comercializar seus produtos ou serviços. Algumas das vantagens oferecidas pelo marketing na internet como comunicação personalizada, que gera mais confiança no consumidor; direcionamento de conteúdo apropriado ao perfil do cliente; maior poder de viralização, já que anúncios que chamam a atenção dos consumidores costumam ser compartilhados; auxiliam empresas a divulgarem os seus negócios, e uma das plataformas online onde as organizações mais encontram resultados são as mídias sociais, onde existe uma grande interação de pessoas e uma rápida movimentação de informações.

O presente trabalho baseou-se a partir de um levantamento bibliográfico em diversos meios de informações constituídos por vários autores. Em seguida, foi realizada uma pesquisa de campo no centro da cidade de Caririaçu - CE, no qual foram lançados questionários a população do município, onde os mesmos foram escolhidos de maneira aleatória. Com a pesquisa foram coletados 245 questionários, e a partir das respostas recebidas foi feita a tabulação e análise dos dados.

Considerando os resultados da análise dos dados, observa-se nos gráficos que uma grande maioria da população possui um conhecimento acerca da ferramenta marketing digital, e que o número de pessoas com acesso as mídias sociais também prevalecem em maioria. Por outro lado, a utilização da ferramenta marketing digital pelas empresas do município ainda se mostra muito limitada, levado em consideração o grande número de entrevistados que afirmaram nunca terem visto algum anúncio do mercado local nas mídias sociais em que utilizam.

Acredita-se na importância dessa pesquisa para o fortalecimento da produção científica acerca de trabalhos futuros e também ampliar o acervo que aborda a realidade da Região Metropolitana do Cariri (RMC) sobre o comércio da cidade de Caririaçu - CE, tendo em vista que a mesma servirá como base de fonte de pesquisa para terceiros que tenham interesse na proposta em debate, e consequentemente, possa dar uma continuidade no tema pesquisa.

\section{Referências}

ALMEIDA, V. N. T; RAMOS, M. S. A. Os Impactos das reclamações On-line da lealdade dos Consumidores: Um estudo Experimental. Revista RAC - Revista de Administração Contemporânea, Rio de Janeiro, v. 16, n. 5, p.664-683, set./out., 2012. 
ALMEIDA, M. L. P. Tipos de pesquisa. In. Como elaborar monografia. 4. Ed. Ver. estual. Belém: Cejup, 1996. Cap. 4, p. 101-110.

AMARAL, S. A. Marketing da informação: entre a promoção e a comunicação integrada de marketing. Informação e Sociedade. v.18, n.1, 31-44, 2008.

ARAUJO, C. A. (2006). Bibliometria: evolução histórica e questões atuais. Em Questão, Porto Alegre, v. 12, n. 1, p. 11-32, jan./jun.

BARATA,L. A nova abordagem do Webmarketingaliada ao comportamento do consumidor.f. 108. Dissertação (Mestrado em Publicidade e Marketing) -Instituto Politécnico de Lisboa, Escola Superior de Comunicação Social, Lisboa, 2011.

CARO, Abrão. Comportamento do Consumidor e a Compra Online: uma análise multicultural. Tese (Pós-Graduação) - Universidade de São Paulo, 2010.

CHLEBA, M. Marketing Digital: novas tecnologias e novos modelos de negócios - São Paulo: Futura, 2000.

Cooper, D. R.; \& Schindler, P. S. (2003). Métodos de pesquisa em administração. Porto Alegre: Bookman.

DRUCKER, P. Management: tasks, resposibilities, preactices. Nova York. Ed. Harper \& Row, 1973. 864p),

FERREIRA, A. B. H. Dicionário Aurélio. Rio de Janeiro: Nova Fronteira, 1986.

FONSECA, J. J. S. Metodologia da pesquisa científica. Fortaleza: UEC, 2002. Apostila.

FRANKENTHAL, Rafaela. Pesquisa Quantitativa e Qualitativa: Qual é a Melhor Opção? 2016. Disponível em: < https://mindminers.com/pesquisas/pesquisa-qualitativa-quantitativa>. Acesso em: 04 nov. 2018.

GARCIA, G.M. Comportamento do consumidor virtual: a influência das características pessoais na intenção de compra. Tese (Pós-Graduação) - Universidade Federal do Rio Grande do Sul, 2007.

GIL, A. C. Como elaborar projeto de pesquisa. 4.ed. São Paulo: Atlas, 2007.

GRÖNROOS, C. Marketing: gerenciamento e serviços. Rio de Janeiro: Campus. 1993.

GRÖNROOS, C. Marketing: gerenciamento e serviços. Rio de Janeiro: Elsevier, 2004.

Instituto de Pesquisa e Estratégia Econômica do Ceará (IPECE): <http://www.ceara.gov.br/2010/03/17/municipios-com-a-letra-c/\#munic-pio-cariria-u> acessado em:03/11/2018 
Instituto Brasileiro de Geografia e Estatísticas (IBGE): $<$ https://canaltech.com.br/internet/brasil-tem-116-milhoes-de-usuarios-de-internet-afirmaibge-108612/> acessado em:03/11/2018

KOTLER, P. Administração de marketing. 10a ed. São Paulo: Prentice Hall, 2000. 764 p.

KOTLER, P. Marketing essencial. São Paulo: Futura, 2005.

LEWANDOWSKI, T. Linguistisches waterbuck. 3. ed. Stuttgart: UTB, 1982.

LOVELOCK, C.; WIRTZ, L. Serviços: marketing e gestão. $6^{a}$ tiragem. São Paulo: Saraiva, 2006.

MALHOTRA, N. Pesquisa de marketing. 3.ed. Porto Alegre: Bookman, 2001.

MANGOLD, W. G.; FAULDS, D. J. Social media: the new hybrid element of the promotion mix. Kelley School of Business, Indiana University: Business Horizons, n. 52, p. 357-365, 2009.

LAKATOS, E. M.; MARCONI, M. A. Fundamentos metodologia científica. 4.ed. São Paulo: Atlas, 2001.

MOLINA, V. L. I. Construindo projetos de pesquisa científica e social. 1. ed. São Paulo: Biblioteca24horas, 2016.

NOVAES, A. G. Logística e gerenciamento da cadeia de distribuição: estratégia, operação e avaliação. Rio de Janeiro: Campus, 2001.

OKADA, I. S.; SOUZA, S. M. E. Estratégias de Marketing Digital na Era da Busca. REMark - Revista Brasileira de Marketing, v. 10, n. 1, p. 46-72, jan./abr. São Paulo, 2011.

PEPPERS, D.; ROGERS, M. Marketing um a um: Individualizando na era do cliente. Rio de Janeiro: Campus, 1994.

PEREIRA, 1. 1. Estratégias de marketing digital utilizadas para o posicionamento de marca e aumento de vendas de uma empresa em Brasília. Faculdade de Tecnologia e Ciências Sociais Aplicadas FATECS. Brasília, 2014.

SANTOS, Glauber Eduardo de Oliveira. Cálculo amostral: calculadora on-line. Disponível em: <http://www.calculoamostral.vai.la>. Acesso em: 02/11/2018

SEGURA, M. C. O estudo do Marketing Digital versus Marketing Tradicional e a percepção das suas campanhas por parte dos consumidores no mercado virtual a tradicional. 2009. f. 51. Dissertação (Mestrado em estatística e Gestão da Informação) Instituto Superior de Estatística e Gestão de Informação da Universidade Nova de Lisboa, Lisboa,2009.

SOMOLON, M. R. O comportamento do consumidor: comprando, possuindo e sendo. 9. ed. Porto Alegre, RS: Bookman, 2011. 
SOUSA; F. J, GOBBI; C.M. Geração Digital: uma reflexão sobre as relações da juventude digital e os campos da comunicação e da cultura. Revista GEMInIS, v. 2, n. 1, p. 129-145, 2014.

TROIANO, J; MARANGONI, N. Os bastidores da história da pesquisa de mercado no Brasil. In: GRACIOSO, Francisco; GALLUCCI, Laura. Marketing no Brasil: introdução e desenvolvimento dos anos 1950 aos dias de hoje. São Paulo: Instituto Cultural - ESPM, p. 108$123,2014$.

VANTI, N. (2002). Da bibliometria à webometria: uma exploração conceitual dos mecanismos utilizados para medir o registro da Informação e a difusão do conhecimento. Ciência da Informação, v. 31, n. 2, p. 152-162.

VAZ, C. A. Google marketing:o guia definitivo de marketing digital.3. ed. São Paulo, SP: Novatec Editora, 2010.

\section{Como citar este artigo (Formato ABNT):}

VILAR, Jose Italo Roseno; QUEIROZ, Herminig Everson Matos; DANTAS, Dávila Maria Feitosa; SILVA, Josefa Zilda Roseno Silva. A Percepção da Utilização do Marketing Digital no Comércio Varejista da Cidade de Caririaçu - CE. Id on Line Rev.Mult. Psic., 2018, vol.12, n.42, Supl. 1, p. 728-748. ISSN: 1981-1179.

Recebido: $14 / 11 / 2018$

Aceito: $17 / 11 / 2018$ 